\title{
O COSMOPOLITISMO KANTIANO E A FUNDAMENTAÇÃO DOS DIREITOS HUMANOS $^{1}$
}

\author{
[THE KANTIAN COSMOPOLITISM AND THE FOUNDATIONS FO HUMAN RIGHTS]
}

\author{
Newton de Oliveira Lima* \\ Universidade Federal da Paraíba, Brasil
}

\begin{abstract}
Resumo: A necessidade do Estado como ordem cogente para organizar a disposição para o convívio em nossa natureza é colocada como uma disposição natural na "Ideia de uma História Universal sob um ponto de vista Cosmopolita" (IaG) em 1784, mas em 1795 em "Rumo à Paz Perpétua" $(Z e F)$ e na "Doutrina do Direito" (RL, 1797), se tornará uma ideia racional cujo fim é o republicanismo, o governo sob uma constituição republicana é o ideal normativo para todo e qualquer povo em sua autolegislação jurídica. Todavia, no plano internacional ocorrem as guerras entre os Estado, e o princípio do cosmopolitismo é possível apenas pela ideia de uma condição jurídica e política criada pelos Estados, os artigos da paz perpétua fundamentam a possibilidade de uma federação de nações que através do Direito Cosmopolita promova a paz pela limitação jurídica da guerra.
\end{abstract}

Palavras-chave: Estado; natureza; paz; cosmopolitismo

\section{INTRODUÇÃo}

Certamente não se pode dizer que Kant construiu uma teoria dos direitos humanos, mas no âmbito sistemático de sua obra emergem teorias da dignidade humana e da proteção jurídico-cosmopolita do indivíduo. Nosso ponto de análise não será uma teoria da dignidade humana em Kant, embora esta funcione como apoio ao seu cosmopolitismo jurídico-político, o que será demonstrado adiante, mas que de início se baseia na assertiva de Kant de que todos os deveres, mesmo os jurídicos, e assim os jurídico-cosmopolitas, são deveres éticos indiretos (KANT, 2005:29, $R L$ AA 06: 220). Nosso foco será no cosmopolitismo jurídico de Kant e

* Professor Adjunto da Universidade Federal da Paraíba, Departamento de Ciências Jurídicas. Doutor em Filosofia pela Universidade Federal da Paraíba-Universidade Federal do Rio G. do Norte-Universidade Federal de Pernambuco, com periodo sandwich na Universidad de Buenos Aires.m@ilto:newtondelima@gmail.com

\begin{abstract}
The necessity of the State as a cogent order to organize the disposition for the conviviality in our nature is placed as a natural disposition in the "Idea of a Universal History 1784, but in 1795 in "Toward a Perpetual Peace" (ZeF) and the "Doctrine of Right" (RL, , will become a rational idea whose aim is constitution is the normative ideal for any and between the States take place, and the principle States, articles of perpetual peace base the possibility of a federation of nations through Cosmopolitan Law promote peace through the legal limitation of war.
\end{abstract}

KEYWORDS: State; nature; peace; cosmopolitism 
alguns de seus reflexos políticos e éticos.

O fato é que Kant enquanto contratalista acredita no acordo de vontades a priori como fundamento da sociedade civil, da conformidade dos arbítrios segundo a lei é que se funda o Direito (KANT, 2005:43, RL AA 06: 230), essa lei é universal para todos aqueles que lhe deram assentimento, no âmbito de dada comunidade.

Os indivíduos são guiados pela ideia de liberdade, que enquanto ideia da razão representa um fim a ser perseguido, e uma ideia reguladora da conduta jurídica na sociedade civil (KANT, 2005: 30, RL AA 06: 221). A formação do pacto político e a regulação da conduta na sociedade civil são conformadas pela ideia de liberdade, a qual recebe na sociedade civil sua expressão coletiva e histórica; para Ricardo Terra (2003, p.127), a Filosofia da História de Kant é a expressão da liberdade jurídica enquanto juízo reflexivo sobre a ideia da liberdade, a História possui um fim que é sua expressão como Direito, Kant (2003, p.10, IaG AA 08:22) proclama na Quinta Proposição (Fünfner Satz) de sua "Ideia de uma História Universal sob um ponto de vista Cosmopolita" (Idee Zu Einer Allgemeinen Geschichte in Weltbürgerlicher Absicht), "O maior problema para a espécie humana, a cuja solução a natureza obriga, é alcançar uma sociedade civil que administre o Direito." (Das grosste Problem für die Menschengattung, zu dessen Auflösung die Natur ihn zwingt, ist die Erreichung einer allgemein das Recht verwaltenden bürgerlichen Gesellschaft. ${ }^{2}$ )

A ideia de uma História universal é movida pela relação de oposição e ao mesmo tempo complementar entre liberdade (Freiheit) e natureza (Natur), a natureza nos dota de instintos e de uma capacidade de ação causal sobre outras causas naturais com as quais interagimos (nós enquanto parte do reino natural também somos submetidos às leis naturais), nesse sentido a natureza é complementar à nossa liberdade, mas também é dissociativa, pois nossa capacidade de ação natural (que gera conflitos com os outros por nosso egoísmo natural) deve ser orientada pela liberdade como ideia condutora da História, a qual é guiada pela razão pura prática que pode dominar as disposições naturais e orientá-las, até mesmo a fim de atingir outra disposição natural, essa boa e não egoísta, que é a paz no convívio humano.

Essa paz, todavia, não prescinde do conflito (Antagonism), mas dele se beneficia pela capacidade de desenvolver nossas disposições em sociedade e assim gerar o progresso, é o que Kant chama de "sociabilidade insociável", que emerge na Quarta Proposição (Vieter Satz) da IaG (KANT, 2003, p. 8, IaG AA 08:19).

$\mathrm{O}$ que regulará o Antagonism na sociedade é a lei moral como dever posto pela consciência racional prática que toma para si móveis de ação (conduta) que possam ser universalizados para todos os seres racionais, assim, a liberdade é guiada pela Ética, e essa capacidade de se conceder normas é estabelecida como autolegislação, daí porque Kant (2008, p.103, GMS AA 04:103) a denominar na Terceira Seção da "Fundamentação da Metafísica dos Costumes" (Grundlegung zur Methaphisik der Sitten) como autonomia (Autonomie), que é o núcleo da dignidade, pois enquanto o ser humano puder autolegislar sua conduta será livre moralmente.

Se cada ser racional possui a capacidade de autolegislar sua conduta como se fosse um querer universal possível de ser querido por todo ser igualmente racional, ele é autor do "Reino dos Fins" (Reichs der Zweche), que é, segundo Dieter Schönecker e Allen Wood (2014,p.147), uma ligação sistemática de leis de liberdade comuns projetadas por todos os seres racionais.

O fundamento ético da História, pelo poder da deliberação racional autônoma, encaminha os homens, que naturalmente pensam em seus interesses particulares movidos por paixões, a buscarem auxílio mútuo na luta contra a necessidade ao comporem uma base econômica da subsistência. A dialética entre a necessidade natural 
e a organização racional da sociedade atinge um nível de racionalização dos conflitos, e a melhor forma de enfrentarem as adversidades é a fundação do ordenamento jurídico, onde seres racionais e livres são co-legisladores.

O Estado jurídico kantiano surge, antes da experiência política real, na representação de um contrato jurídico em que todos os indivíduos dele pactuantes se tornam cidadãos legisladores ao nele ingressarem inteligivelmente. A ideia de um pacto jurídico regulará a realização da Constituição efetiva (histórica). Assim, o impulso de autonomia moral passa a ser expresso, pela necessidade que a natureza impõe, como sociedade civil, regulatória da liberdade de querer objetos externos à consciência, a liberdade externa que Kant (2003, p.11, IaG AA 08:23) projeta que seja protegida pelo Estado, daí a necessidade de um senhor (Herrn), o Estado é esse senhor, esse poder que assoma sobre a natureza para regular cogentemente os conflitos e organizar a base econômica da sociedade.

A necessidade do Estado como ordem cogente para organizar a disposição para o convívio em nossa natureza, é colocada como uma disposição natural na "Ideia de uma História Universal sob um ponto de vista Cosmopolita" (IaG) em 1784, mas em 1795 em "Rumo à Paz Perpétua" $(Z e F)$ e na "Doutrina do Direito" $(R L, 1797)$, se tornará uma ideia racional cujo fim é o republicanismo, o governo sob uma constituição republicana é o ideal normativo para todo e qualquer povo em sua autolegislação jurídica.

Esse poder estatal uma vez constituído exige submissão à lei, pensada a vontade do povo como sua última legitimação (KANT, 2005, p. 179, RL AA 06: 313), contra esse poder não é possível resistir, pois é irracional voltar ao estado de insegurança natural, da guerra de todos contra todos que já obsevara Thomas Hobbes. Cabe a esse Estado jurídico assegurar o direito e a liberdade externa conforme a lei aos seus cidadãos, o Direito Público regula o Direito Privado mediante leis públicas, assegurando os limites jurídicos do meu e do teu.

Ainda que o Estado tenha elementos autoritários, ele possui a obrigação de se republicanizar, adequando seus princípios aos de uma Constituição republicana, isso necessita um "reformismo constante" (KANT, 2005, p.245, RL AA 06: 355) que confia em um "governo das leis" e não "dos homens" como o mais republicano, um movimento incessante de garantir aos cidadãos igualdade, liberdade e independência através da lei, controlando o poder do Estado.

$O$ fato da reforma constante em direção ao ideal republicano ser uma obrigação de todo Estado, implica uma modelação interna rumo à ordem justa enquanto ordem republicana (KANT, 2005, p.223, §52, RL AA 06: 340), mas isso não afasta o perigo da guerra de um Estado com outro. Sempre haverá a possibilidade do conflito, tanto interno por uma secção civil, mas principalmente externo, pela disputa entre os Estados por poder. E o Direito Internacional Público ("Direito das Gentes" para Kant, 2005, p.238, §61, RL AA 06: 350) não pode por si, enquanto se mover na arena patriótica de cada Estado nacionalista, evitar a guerra, e não atinge seu fim que é a paz, que é quando os Estados podem mirar não seus próprios interesses, mas os da humanidade (KANT, 2010, p.24, ZeF AA 07:349). A ideia da humanidade na $Z e F$ em 1795 recebe uma formulação jurídica, aperfeiçoando a noção de ideia da humanidade como fim ético expresso na $I a G$ em 1784, aqui Kant partiu do conceito de espécie humana para abstrair a ideia de humanidade como conceito ético universal, na $\mathrm{ZeF}$ a humanidade já é um fim ideal do projeto cosmopolita supra-nacional.

Em "A Religião nos limites da simples Razão" (Die Religion innerhalb der Grenzen der blossen Vernunft) de 1793 a ideia de humanidade já aparece como sagrada no sentido de aperfeiçoamento ético a partir de uma limitação racional do sumo bem 
religioso em nós (KANT, 1992, p.90, $\operatorname{Rg} V$ AA 06:84) e cada homem deve buscar o aperfeiçoamento ético como se dependesse somente de si e não de qualquer intervenção sobrenatural, portanto, o aprimoramento ético depende somente do uso individual de nossa simples razão prática (KANT, 1992, p.94, $R g V$ AA 06:88). É a etapa conclusiva de uma Filosofia da História que se despende do transcendente e fixa na ação livre e responsável (imanente) do homem na História. Ambas as finalidades, a humana posta pela razão, e a natural, são complementares, e levam à consecução do sumo bem político, a paz.

O plano político entre os Estados é análogo ao plano natural para os indivíduos, há um conflito constante e uma busca pelo poder, que só pode ser racionalizado pela erigição de uma sociedade de nações. Diz Kant (2005, p.239, §61, RL AA 06: 351) que a obtenção de uma tal sociedade de nações é algo jurídico-processual e não forçoso como a barbaridade da guerra.

Kant mantém a distinção entre ser (fato natural da guerra entre nações) e deverser (ordenamento jurídico entre as nações construído processualmente), a fim de preparar a fundamentação jurídica de seu cosmopolitismo, já que não se pode obter a paz através da mera amistosidade entre nações sem um núcleo jurídico protetivo da paz, como ele observa (KANT, 2005, p.239, §61, RL AA 06: 350) o fracasso do congresso de nações em Haia em meados do séc. XVIII, em que à base de simples amizade entre nações não se atingiu qualquer resultado jurídico ou político efetivo, portanto, do plano moral não se origina a paz entre as nações, a crítica aos jusnaturalismos (Grotius, Vattel, Puffendorf) sem eficácia jurídica que o precederam ocorreu também em "Rumo à Paz Perpétua" (KANT, 2010, p.33, ZeF AA 08:355).

O cosmopolitismo em Kant decorre, pois, não de uma especulação jusnaturalista ou de uma filantropia benéfica de amor à humanidade, mas de projeto de estrutura normativa que possui plena consciência de sua historicidade, politicidade e, conseguintemente, juridicidade. São fontes do projeto cosmopolita de Kant a $I a G$, a $Z e F$ e a $R L$.

\section{O COSMOPOLITISMO DE KANT}

A grande obra sobre o cosmopolitismo sem dúvida é a $Z e F$, que ficou assaz conhecida como fonte do liberalismo kantiano, de uma defesa da razão pública, do livre-mercado, do republicanismo e, principalmente, como fonte do Direito Cosmopolita kantiano que iria inspirar a ONU e a Liga das Nações no século XX.

No entanto, na $I a G$ em 1784, já fora traçada a teoria da História de caráter imanentista, e a condução da História humana compete somente aos próprios homens sem contar com um fim maior transcendente, mas podendo atingir um sumo bem, que é a paz e assegurar a liberdade moral de cada qual, fundando para protegê-la uma sociedade universal que administre o Direito. Isso aperfeiçoa o fim maior que é o desenvolvimento (moral) da ideia de humanidade.

$\mathrm{Na}$ Oitava Proposição (Achter Satz) da IaG a confiança que o Iluminismo levará a uma majoração da moralidade de todos os homens se fortalecerá a partir de cada Estado, pela capacidade de vivência da liberdade pelos cidadãos no esforço de republicanizar as condições políticas internas de sua nação (KANT, 2003,p.18, IaG AA 08:28).Esse espírito do Esclarecimento (Aufklärung) leva ao despertar do interesse pela humanidade, gerando a esperança de reconhecer aquilo que a natureza tem como propósito supremo, a erigição de um Estado cosmopolita universal (allgemeiner weltbürgerlicher), onde se poderão desenvolver as disposições originais da espécie 
humana (KANT, 2003, p. 19, IaG AA 08: 28).

$\mathrm{Na} Z e F$ e na $I a G$ Kant pensa no futuro, alarga o espírito do Esclarecimento como um projeto que pode ser lançado adiante para moralizar a humanidade, mas que não possui nenhuma garantia de que ocorrerá, a não ser a racionalidade e garantia jurídica formuladas pela republicanização dos Estados. Por isso que na $Z e F$ a republicanização é uma obrigação universal, que depende da razão pública de cada povo, mas aparece em definitivo a perspectiva cosmopolita, que apela a uma razão cosmopolita, supra-estatal. No âmbito da razão cosmopolita inaugurada pelas condições ofertadas na $Z e F$, Kant introduz o princípio da democracia como acesso de todos os homens aos princípios públicos da razão, onde não há mais sequer o senhorio do Estado nacional e sua verdade constitucional, mas as razões passam a ser acessíveis a todos, numa metacrítica da razão científica, acadêmica e mesmo a filosófica, como aponta Heck (2009, p.107-108).

Nenhuma máxima de razão particular pode se furtar ao princípio da publicidade, afinal para Kant a natureza da razão é pública, e por isso sujeita ao exame crítico por todos, mas não significa que o princípio da maioria tenha a última palavra na verdade, mas que todos possam examinar as proposições do discurso e daí a verdade aparecerá pela crítica exercida sobre as premissas expostas (HECK, 2009, p. 107-108).

O princípio do cosmopolitismo é possível apenas pela ideia de uma condição jurídica e política criada pelos Estados, os artigos preliminares da paz perpétua (KANT, 2010, p.14-19, ZeF AA 08:343):

$1^{\circ}$ Proibição de acordos entre Estados com cláusulas secretas (publicidade contratual estatal); Estados;

$2^{\circ}$ Não patrimonialismo entre Estados e respeito à auto-determinação dos

$3^{\circ}$ Desarmamentismo. Supressão dos exércitos permanentes dos Estados;

$4^{\circ}$ Não endividamento com fins colonialistas pelos Estados; anti-colonialismo.

$5^{\circ}$ Não-agressão entre Estados (pacifismo);

$6^{\circ}$ Proibição de crimes de guerra entre Estados com uso de expedientes antihumanitários.

Os artigos definitivos encaminham ao princípio republicano cosmopolita:

$1^{\circ}$ A Constituição civil em cada Estado deve ser republicana (Die bürgerliche Verfassung in jedem Staate soll republikanish sein); desse artigo decorre diretamente o cosmopolitismo kantiano, "a constituição segundo o direito cosmopolita, enquanto homens e Estados que, estando em relação de influência mútua exterior, têm de ser considerados como cidadãos de um Estado universal da humanidade (ius cosmopoliticum)" (die nach dem Weltbürgerrecht, so fern Menschen und Staaten, in äusserem auf einander einfliessendem Verhälttniss stehend, als Bürger eines allgemeinen Menschenstaats anzusehen sind (ius cosmopoliticum). (KANT, 2010, p.24, ZeF AA 08: 349)

$2^{\circ} \mathrm{O}$ direito internacional deve fundar-se em um federalismo de Estados livres (Das Völkerrecht soll auf einen Föderalism freier Staaten gegründet sein); cujo objetivo é fundar uma liga de paz (foedus pacificum) que teria como objetivo fazer cessar as guerras permanentemente(KANT, 2010, p.31, ZeF AA 08:354);

$3^{\circ} \mathrm{O}$ direito cosmopolita deve ser limitado às condições da hospitalidade universal (Das Weltbürgerrecht soll auf Bedingungen der allgemeinen Hospitalität eingeschränkt sein), que significa um direito de visita de todo ser humano a qualquer parte da humanidade, concebendo-se a posse comunitária da superfície da Terra, devendo os homens tolerar-se mutuamente, pois ninguém tem mais direito de estar em qualquer lugar que outro (KANT, 2010, p.37, ZeF AA 08:357). 
O que pode emergir como cidadania mundial advém da possibilidade de assegurar uma federação de Estados constituída pelo livre-consentimento dos mesmos, com um Direito Cosmopolita nascido desse contrato jurídico específico para proteger a paz de modo perpétuo, de proibir juridicamente as guerras entre aqueles que adiram ao pacto cosmopolita e de rechaçar agressões de inimigos injustos (Estados despóticos). $\mathrm{O}$ direito cosmopolita é decorrente da ideia da representação da totalidade da espécie humana, unificando os outros dois âmbitos, o jurídico interno a cada Estado, e o internacional, formado pela pluralidade dos Estados. A partir daqui se pode cogitar um Estado ou República mundial, conforme Nour (2013, p.55). Mas não é um Estado unificado, Kant não aceita tal propósito por reconhecer a diferença cultural dos povos (NOUR, 2013, p.53), o que inclusive o leva a combater o colonialismo, condenando a invasão européia a outros povos (NOUR, 2013, p. 58).

O sentido do que é a República mundial é que ela é uma "Federação de Nações", em que se têm a formação e a manutenção desse pacto jurídico e sua função de proteção mútua dos Estados membros e de seus cidadãos.

Assim, como diz Heck (2009, p.109), há uma base ética no cosmopolitismo de Kant que remonta aos estóicos e cínicos, pois para eles, assim como para Kant, cada ser humano natural é um cidadão do mundo (kosmou polités). Wolfgang Kersting (2003,p.93), com fundamento de Kant, também frisa que a base de reconhecimento dos direitos humanos a todos os seres racionais que pela natureza apresentem a forma e a racionalidade humanas, o homem natural, o homem nu tomado em si como base do reconhecimento moral e jurídico de seu valor, remete a um naturalismo a base de fundamentação dos direitos humanos (KERSTING, 2003,p.93).

Os Estados devem reconhecer a dignidade humana num aspecto jurídico simplesmente por um indivíduo ser um fím em si moral, defendi essa posição em 2010 no XII Colóquio Kant - Direito e Política - da Sociedade Kant - Seção Campinas, em uma comunicação intitulada "Kant e a fundamentação de um direito à autonomia moral". Isso implica na proteção dos direitos humanos pela proibição de violar os "direitos dos homens" e tratar os seres humanos como meios e não como fins em si (KANT, 2008, p. 74, GMS AA 04:68), "não posso dispor do homem na minha pessoa para o mutilar, o degradar ou o matar" (KANT, 2008, p. 73, GMS AA 04:67).

Para Kant não basta a cidadania interna republicana, mas a partir do que emana do $1^{\circ}$ artigo definitivo para a paz perpétua da $Z e F$, há uma relação entre poder dos Estados e condição humana que não pode ser desprezada, a elevação dessa relação entre Estado e indivíduo está expressa na proteção sistemática que a $Z e F$ confere a uma leitura moral da política através do Direito, a política e, portanto, o exercício do poder estatal sobre qualquer indivíduo, deve ser limitada às condições do Direito.

O cosmopolitismo de Kant já implica, mesmo partindo da esfera jurídica pura de um Direito Republicano que parte de cada Estado, em uma cultura de respeito ao cidadão do mundo que é todo aquele que na prática mostra interesse em ingressar em outro território que não o de seu país, como é o caso dos refugiados de guerra ou de catástrofes naturais. Se Kant exige que há em tese um livre acesso de qualquer ser humano a qualquer território, não há uma posse exclusiva sobre qualquer território no mundo por parte de qualquer Estado, qualquer cidadão que necessite de asilo pode requerê-lo, e cada Estado, pelo dever de hospitalidade, deve a priori concedê-lo.

A partir da análise da hospitalidade universal, que no terceiro artigo permanente da paz perpétua é o âmbito do exercício do direito cosmopolita pelo cidadão, percebe-se um delineio em Kant de direitos humanos análogos aos contemporâneos direitos humanos no sentido de um acesso à comunicação pelos indivíduos (NOUR, 2013,p. 147), representa a abertura à exigência de direitos pelo cidadão, a diminuição do 
"segredo de Estado" e o declínio da doutrina das "razões de Estado", há de se aplicar o princípio da máxima publicidade que Kant (2010,p.75) traça no II apêndice da $Z e F$ (AA 08: 381).

Por essa linha de raciocínio os direitos humanos em Kant teriam um conteúdo aberto, sem uma especificação taxativa ou enclausuladora, mas procurando limitar o excesso de poder do Estado, portanto, uma diminuição da soberania e um crescimento das garantias processuais e constitucionais jurídicas do cidadão, aumentando as expectativas de proteção à liberdade e à dignidade humanas (NOUR, 2013, p. 148-149).

\section{CONCLUSÃo}

Assim, assoma da Filosofia Política a possibilidade de construir a proteção aos direitos humanos e dos refugiados pela aplicação dos princípios do Direito Racional, não de uma visão enumerativa de direitos, mas de concessão de uma proteção jurídica a qualquer cidadão que se encontre necessitado de abrigo, proteção física ou necessidade de meios urgentes de subsistência decorrentes de perseguição por guerra, e a cultura de paz decorrentes da cidadania cosmopolita, a aliança entre direito e ética só pode ser entendida em função da estabilização do Estado mundial proposto por Kant no decorrer do exercício de uma cooperação de paz entre os Estados, que decorre das imprecações da ZeF: obrigação interna de cada Estado de se republicanizar e constituir um fundo institucional de pacificação federativo no plano cosmopolita.

O reformismo político interno e a democracia como meta interna de ampliação do acesso aos direitos, geram o esforço e a expectativa de paz previstas na $I a G$. As consequências de pensar direitos humanos na tradição kantiana para o campo cosmopolita são frutíferas, se feitas sem retórica demagógica política, mas cumprindo um esforço de ganho de autonomia ética e jurídica dos "cidadãos do mundo", decorrente da centralidade deles como sujeitos protagonistas do Direito Internacional (não apenas os Estados) pelo reconhecimento dos direitos humanos como limitadores da soberania guerreira e autoritária dos Estados, como defende Habermas (2005, p.3233) completando o projeto kantiano. Para Habermas (2005, p.90-91) a efetiva proteção à dignidade dever ser reconhecida através dos direitos fundamentais à luz de sua forma jurídico-positiva e não como meros direitos humanos morais, que seriam fundamentados a partir de seu pretenso conteúdo justo.

$\mathrm{O}$ caso dos refugiados de guerra é um bom exemplo de como pode se pensar na dignidade humana como base de um direito cosmopolita efetivo, protegido pelos Estados e com vistas a, quando se proteger os refugiados, criar-se um anteparo aos arbítrios estatais e um esforço de redução dos conflitos, aproximando-se do ideal normativo kantiano da paz perpétua.

\section{REFERÊNCIAS}

\subsection{Obras de Kant}

Obras de Immanuel Kant conforme a Akademie Ausgabe von Immanuel Kants Gesammelten Werken Bande und Verknepfungen zu den Inhaltsverzeichnisse. Fonte: www.korpora.zim.uni-duisburg-essen.de. Acesso: 16.04.2017. 
GMS Grundlegung zur Metaphysik der Sitten (AA 04)

(Cito tradução de Paulo Quintela: Fundamentação da metafísica dos costumes. Lisboa: Edições 70, 1986.)

IaG Idee zu einer allgemeinen Geschichte in weltbürgerlicher Absicht (AA 08)

(Cito tradução de Rodrigo Naves; Ricardo Ribeiro Terra: Ideia de uma História Universal de um ponto de vista Cosmopolita. São Paulo: Martins Fontes, 2003.)

MS Die Metaphysik der Sitten (AA 06)

RL Metaphysische Anfangsgründe der Rechtlehre (AA 06)

(Cito tradução de José Lamego: A Metafísica dos Costumes. Princípios metafísicos da doutrina do Direito. Lisboa: Fundação Calouste Gulbenkian, 2005.)

ZeF Zum ewigen Frieden (AA 08) (Cito tradução de Artur Morão. A paz perpétua e outros opúsculos. Lisboa: Edições 70, 2004.)

\subsection{Referencias secundárias}

HABERMAS, J. La paix perpétuelle - le bicentenaire d'une idée kantienne. Tradução de Rainer Rochlitz. Paris: Les éditions du Cerf, 2005.

HECK, J.N. Ensaios de Filosofia Política e do Direito: Habermas, Rousseau e Kant. Goiânia: Ed. da Universidade Federal de Goiás, 2009.

KERSTING, W. Universalismo e Direitos Humanos. Tradução de Drayton Gonzaga de Souza. Porto Alegre: EdPUC-RS, 2003.

LIMA, N.O. Kant e a fundamentação de um direito à autonomia moral. In: Caderno de resumos do XII Colóquio Kant - Direito e Política - Sociedade Kant - Seção Campinas, 26 a 29 de Julho de 2010. Campinas: EdUnicamp, 2010, p.1-44.

NOUR, S. À Paz Perpétua de Kant. Filosofia do Direito Internacional e das relações internacionais. São Paulo: Martins Fontes, 2003.

SCHÖNECKER, D.; WOOD, A. A Fundamentação da metafísica dos costumes de Kant - um comentário introdutório. Tradução de Robinson dos Santos e Gerson Neumann. São Paulo: Loyola, 2014.

TERRA R. R. Passagens. Estudos sobre a Filosofia de Kant. Rio de Janeiro: EdUFRJ, 2003. 